\title{
Research on Energy Dissipation Laws of Coal Crushing under the Impact Loads
}

\author{
Dengke Xu $\mathbb{D},{ }^{1}$ Chaomin $\mathrm{Mu} \mathbb{D},{ }^{2,3}$ Wenqing $\mathrm{Zhang},{ }^{2,3}$ and Zhongqing $\mathrm{Li}^{2,3}$ \\ ${ }^{1}$ School of Civil Engineering and Architecture, Anhui University of Science and Technology, Huainan, Anhui 232001, China \\ ${ }^{2}$ School of Safety Science and Engineering, Anhui University of Science and Technology, Huainan, Anhui 232001, China \\ ${ }^{3}$ Key Lab of Mining Coal Safety and Efficiently Constructed by Anhui Province and Ministry of Education, Huainan, \\ Anhui 232001, China \\ Correspondence should be addressed to Chaomin Mu; chmmu@mail.ustc.edu.cn
}

Received 21 February 2021; Revised 1 June 2021; Accepted 9 June 2021; Published 21 June 2021

Academic Editor: Qi ZHAO

Copyright (C) 2021 Dengke Xu et al. This is an open access article distributed under the Creative Commons Attribution License, which permits unrestricted use, distribution, and reproduction in any medium, provided the original work is properly cited.

\begin{abstract}
Dynamic crushing characteristics of coals are closely related with energy absorption and release of coals under certain strain rate. Hence, it is necessary to investigate energy dissipation laws of coal crushing under the impact loads with different strain rates. Based on the dynamic and static mechanical tests, crushing energy, total absorption energy, total releasable elastic latent energy, and relations between fractal feature of fragments, mean particle diameter and energy during crushing behaviors of outburst coal and nonoutburst coal were investigated. According to research results, crushing energy, total absorption energy, and releasable elastic latent energy of outburst coal and nonoutburst coal are related with strain rate, and they present exponential growths with the increase of the strain rate. However, the energy dissipation rate (ratio of crushing energy and incident energy) was basically constant at about $10 \% \sim 20 \%$, that is, energy dissipation rate is a variable unrelated with strain rate. There is a good logarithmic relationship between the dynamic compressive strength of coals and the absorption energy density and elastic latent energy density, and dynamic comprehensive strength of coals has important impacts on energy absorption. The fractal features of coal fragments were obvious under dynamic impacts. The higher fractal dimension of fragment and the smaller mean particle diameter of experimental fragments bring the greater energy needed.
\end{abstract}

\section{Introduction}

Coal resources have been occupying the dominant role in the world energy structure. With the increase of coal mining depth, the coal seams are exposed to increasingly complicated occurrence conditions. Coals might accumulate more energy, and coals might bear strong impact loads upon sudden loading disturbances during uncovering, explosion, and advancing processes of coals, thus resulting in coal and rock dynamic disasters represented by coal-gas outburst and rock burst, etc. [1-4]. To prevent and decrease occurrences of such dynamic disasters, it is necessary to understand mechanical properties of coal and rock materials under dynamic loads. In the past few decades, the mechanism of coal deformation and failure has been extensively investigated through laboratory tests, such as uniaxial [5], biaxial
[6], and triaxial [7] compression, dynamic tensile [8], and cyclic impact loading [9]. The split Hopkinson pressure bar (SHPB) is considered to be a commonly used experimental device for the study of rock dynamic fragmentation process $[10,11]$.

Recently, many studies focus on the relations of coal deformation and fractures with energy. The dynamic crushing characteristics of materials are closely related to the energy absorption and release at a certain strain rate. The mechanism of coal outburst can be understood by accurately calculating the crushing energy and surface energy of coal. The fractal theory relating the coal particle size was developed to calculate the crushing energy of coal. The fractal model and crushed coal particle size distribution data fitted, and a kinetic equation was formulated to describe the particle size distribution for two types of coal [12]. The effect 
of impact speed on the crushing energy and particle size distribution was investigated, and we found that the degree of fragmentation increases exponentially with impact speed [13]. Luo et al. [14] evaluated the energy for crushing coal to various size fractions in coal and gas outbursts through theoretical and experimental investigation of the shape of fine coal particles and their equivalent diameter. Many foreign researches has also investigated the relationship between crushing energy and particle size distribution using different methods, such as numerical simulation $[15,16]$ and vertical impact $[17,18]$. The model and law of crushing ratio were proposed to evaluate coal crushing efficiency $[19,20]$. In the crushing process of materials under external loading, the surface energy is a component of the crushing energy. The surface area of fragment is often used to measure the surface energy during crushing [21-24].

Coal crushing involves energy release and dissipation, including energy absorption, transformation, and release. The releasable strain energy is the driving force for the failure of coal or rock mass structure, and the crushing energy is related to the damage degree of coal or rock mass structure in the plastic zone [25-27]. The effects of water contents and incident energy levels on coal dynamic behavior were studied. The results indicate that dynamic strength and elastic modulus positively correlated with the incident energy. The incident energy-dominated and energy-induced failures were analyzed based on dissipation energy and stress-strain curve types [28]. Feng et al. [29] proposed the energy dissipation rate as a novel indicator of coal deformation and failure under static and dynamic compressive loads. The relationship between stress-strain, uniaxial compressive strength, displacement, loading, and energy dissipation rates and fractal dimension was investigated. The results showed that the peak value of energy dissipation rate is associated with stress drop during coal deformation, as well as to the uniaxial compressive strength. Hao et al. [30] analyzed the energy accumulation, energy rate of release, and failure modes of hard coal under dynamic, static, and coupled dynamic-static loading. The results showed that the degree of destruction and fragmentation of coal samples increases with the increase of prepeak energy accumulation. The first attempt by numerical methods was made in investigating the energy release during the failure of pillarscale coal mass samples with varying cleat densities. The results indicate that cleat spacing can have a significant impact on the compressive strength and energy release, in which both strength and energy release (magnitude and rate) decrease as the number of cleats increases [31]. An effective elastic strain energy release rate index was proposed to evaluate the coal bursting liability and fully integrate the energy evolution of coal samples being damaged by loading. Results show that the propagation and coalescence of cracks are accompanied by energy release [32]. A simple and novel analytical solution was developed to calculate the amount of released energy under varying joint density, and three-dimensional numerical simulation was conducted to understand the influence of coal's joint and cleat characters (directions and densities) on the possible energy release and/ or dissipation [33]. To determine the relationship between energy transformation and coal failure, we established the damage evolution model of the rigidity degeneration of coal before the peak strength based on the test results. The results reveal that failure energy ratio is approximately linearly related to the fractal dimension of the coal fragments, and a high failure energy ratio corresponds to a large fractal dimension and severe failure [34]. In conclusion, the energy consumption of dynamic failure and static failure differ under the same damage or breakage degree.

Previous associated studies mainly emphasize on mechanical properties, degree of fragmentation, and total energy of coals and rocks under different strain rates. Only few have discussed the energy absorption and releasing mechanism of coals and rocks under different strain rates as well as the relationship between mean particle diameter of crushing coal and energy density. Based on uniaxial static compression and SHPB dynamic impact experiment, crushing energy, total absorption energy, and total releasable latent energy of different coal samples (different strengths) under dynamic and static loads were gained. Moreover, energy characteristics under different strain rates were compared, and the energy dissipation laws of different strengths coals with crushing under the impact loads were gained.

\section{Experimental Method}

2.1. Sample Preparation. Outburst coal is the low strength coal formed after the raw coal is crushed and bonded under the ground stress because it is difficult to core on-site; therefore, imitating the formation process of outburst coal in nature, that is, the crushing and bonding method, is used to reconstruct the outburst coal in the laboratory. Nonoutburst coal is the raw coal with high strength. In this experiment, coal samples were collected from the 13-1 coal seam, Zhangji Coal Mine, Huainan Mining Group. Outburst coal specimen is made by grinding raw coal, sifting 40 80 mesh coal powers, and then shaping with $100 \mathrm{MPa}$ pressure on a large rigid press machine with a self-made coal pressure tank. The nonoutburst coal specimen is made by drilling on the raw coal by a rock drill, and then grinding and cutting into the cylindrical coal mass with a diameter of $50 \mathrm{~mm}$. The cylinder specimens with a height of $100 \mathrm{~mm}$ and a diameter of $50 \mathrm{~mm}$ were used in the static uniaxial compression experiment, in which the nonoutburst coal specimens were numbered S1 S3 and the outburst coal specimens were numbered S4 and S5. The cylinder specimens with a height of $30 \mathrm{~mm}$ and a diameter of $50 \mathrm{~mm}$ were chosen in the dynamic impact experiment, in which the outburst coal specimens were numbered D1 D14 and the nonoutburst specimens were numbered D15 D20.

2.2. Experimental System. Failure characteristics of coals under static loads were concluded from the static uniaxial compression experiment of coal specimens on the RMT-350 rock mechanical testing system in the Mining Engineering Laboratory of the Anhui University of Science and Technology. Mechanical properties of coals under dynamic loads 
were gained through a dynamic impact experiment based on the $\Phi 75 \mathrm{~mm}$ SHPB in the Impact Laboratory of the Anhui University of Science and Technology. Diameters of the trip rod (bullet), incidence rod, and output rod of the SHPB system were determined to be $75 \mathrm{~mm}$, whereas lengths were $0.4 \mathrm{~m}, 4 \mathrm{~m}$ and $2.5 \mathrm{~m}$, respectively. They were all made of high-strength alloy steel, and the elasticity modulus was $195 \mathrm{GPa}$. Physical picture of experimental system is shown in Figure 1.

2.3. Experimental Procedures. The static uniaxial compression loading rate of outburst coal and nonburst coal specimens was $0.02 \mathrm{~mm} / \mathrm{s}$. A dynamic impact test was carried out to test dynamic characteristics of outburst coal and nonburst coal specimens under different impact loads. In the impact experiment of nonoutburst coals, the pneumatic control of driving device was controlled at $0.2 \sim 0.6 \mathrm{MPa}$, and the corresponding impact speed of the bullet was $4.36 \sim 6.15 \mathrm{~m} / \mathrm{s}$. A total of 6 groups of effective data were gained successfully. In the impact experiments of outburst coals, the pneumatic control of driving device was controlled at $0.2 \sim 0.7 \mathrm{MPa}$, and the corresponding impact speed of the bullet was $3.21 \sim 10.81 \mathrm{~m} / \mathrm{s}$. A total of 14 groups of effective data were gained.

\section{Energy Composition in the SHPB Compression Experiment}

3.1. Energy Carried by the Stress Wave. The Hopkinson bar (SHPB) technology is based on the one-dimensional elastic stress wave theory and the hypothesis of uniformity. The energy carried by the stress wave $\sigma(t)$ is expressed as

$$
\begin{aligned}
W & =\frac{A_{e} C_{e}}{E_{e}} \int_{0}^{t} \sigma^{2}(t) \mathrm{d} t=\frac{A_{e} C_{e}}{E_{e}} \int_{0}^{t}\left[E_{e} \sigma(t)\right]^{2} \mathrm{~d} t \\
& =A_{e} E_{e} C_{e} \int_{0}^{t} \varepsilon^{2}(t) \mathrm{d} t,
\end{aligned}
$$

where $A_{e}$ is the cross sectional areas of the input and output bars $\left(\mathrm{m}^{2}\right), E_{e}$ is the elasticity modulus of the input and output bar materials $(\mathrm{GPa}) . \mathrm{C}_{e}$ is the speed of one-dimensional stress wave and speed of stress wave $\left(C_{e}\right)$ in the elasticity stage can be expressed by the mass density $\left(\rho_{e}\right)$ and elasticity modulus $\left(E_{e}\right)$ of the compression bar: $C_{e}=\sqrt{E_{e} / \rho_{e}}$. For this SHPB test system, $C_{e}=4984 \mathrm{~m} / \mathrm{s} . \varepsilon(t)$ is the strain corresponding to the stress wave.

The incident energy $\left(W_{I}\right)$, transmitted energy $\left(W_{T}\right)$, and reflected energy $\left(W_{R}\right)$ on the compression bar from loading to unloading could be expressed as the following equations:

$$
\begin{aligned}
& W_{I}=A_{e} C_{e} E_{e} \int_{0}^{t} \varepsilon_{I}^{2}(t) \mathrm{d} t, \\
& W_{R}=A_{e} C_{e} E_{e} \int_{0}^{t} \varepsilon_{R}^{2}(t) \mathrm{d} t, \\
& W_{T}=A_{e} C_{e} E_{e} \int_{0}^{t} \varepsilon_{T}^{2}(t) \mathrm{d} t,
\end{aligned}
$$

where $\varepsilon_{I}(t), \varepsilon_{R}(t)$, and $\varepsilon_{T}(t)$ are strains corresponding to the incident wave, reflected wave, and transmitted wave on the compression bar.

3.2. Crushing Energy and Crushing Energy Density. Because the two end surfaces of specimens were coated with lubricant, energy consumed by the frictional force between contact surfaces was ignored in the analysis. As a result, the energy carried by the incident wave minus the sum of energy carried by the reflected wave and the transmitted wave is equal to the energy consumed by failure of specimens under dynamic impacts. This is called the crushing energy of specimens, and it can be calculated as follows [35]:

$$
W_{D}=W_{I}-\left(W_{R}+W_{T}\right)=A_{e} C_{e} E_{e} \int_{0}^{t}\left[\varepsilon_{I}^{2}(t)-\varepsilon_{T}^{2}(t)-\varepsilon_{R}^{2}(t)\right] \mathrm{d} t .
$$

Dissipated energy in unit volume was used to measure the energy consumption during impact-induced failure, which is known as the crushing energy density $\left(w_{D}\right)$ :

$$
w_{D}=\frac{W_{D}}{V},
$$

where $V$ is the volume of specimens $\left(\mathrm{m}^{3}\right)$.

3.3. Energy Dissipation Rate. The ratio of crushing energy and incident energy was defined as the energy dissipation rate $(N)$ to measure energy dissipation strength of coals and rocks under varying strain rates:

$$
N=\frac{W_{D}}{W_{I}} \times 100 \% .
$$

3.4. Total Absorption Energy and Releasable Elastic Latent Energy. According to the theory of rock mechanics, the area enclosed by the stress-strain curves gained from the static loading experiment and dynamic experiments was the failure-induced absorption energy density $(u)$ of specimens during the loading process:

$$
u=\int \sigma \mathrm{d} \varepsilon,
$$

where $u$ is the failure-induced absorption energy density of specimens $\left(\mathrm{J} / \mathrm{m}^{3}\right)$ and $\sigma$ is the coal-rock stress (MPa).

Then, the total absorption energy $(U)$ of specimens during the failure process is

$$
U=u V,
$$

where $V$ is the volume of specimens $\left(\mathrm{m}^{3}\right)$.

When coal-rock specimens are exposed to external loads, it is hypothesized that the deformation formation has no heat exchange with the external world. The total energy $(U)$ that is applied by the external force on the specimens can be expressed as

$$
U=U^{\mathrm{d}}+U^{\mathrm{e}},
$$




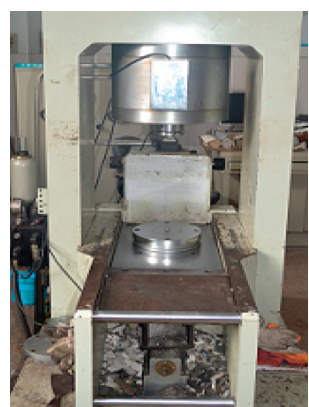

(a)

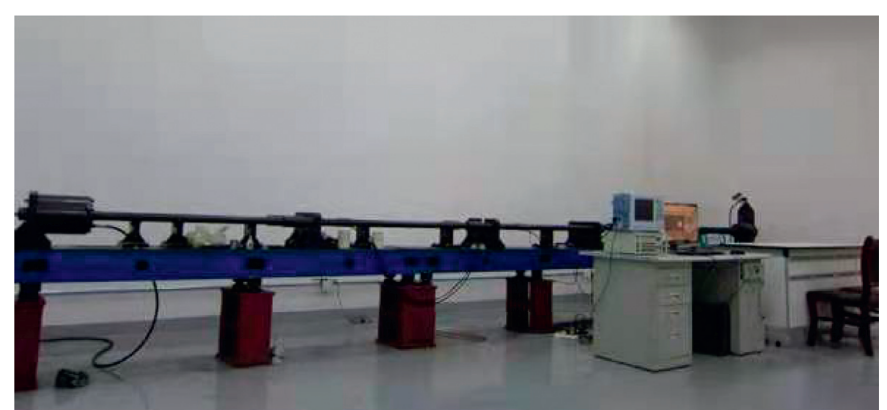

(b)

Figure 1: Physical picture of experimental system. (a) RMT-350; (b) $\Phi 75 \mathrm{~mm}$ SHPB.

where $U^{\mathrm{d}}$ is the dissipated energy of specimens during crushing, which is mainly to form internal damages and plastic deformation of specimens. $U^{\mathrm{e}}$ is the releasable elastic latent energy of specimens, and it is directly related with unloading elasticity modulus and unloading Poisson's ratio. Obviously, energy dissipation is one-way and irreversible, whereas releasable elastic latent energy is reversible. The relationship between energy dissipation and releasable elastic latent energy is reflected on the stress-strain curves (Figure 2).

\section{Results and Discussion}

4.1. Macroscopic Analysis of Impact Failure of Coals. Failure modes of nonoutburst coal and outburst coal under different strain rates are shown in Figure 3. According to comparison, the nonoutburst coal fragments are uniform when the strain rate is $81 \mathrm{~s}^{-1}$, and there is no significant block. With the increase of strain rate, the energy carried by the stress wave is enough to generate longitudinal runthrough cracks on specimens, thus intensifying the degree of crushing. From the perspective of energy, both crack initiation and expansion in materials requires energy dissipation, whereas the energy needed for the formation of new cracks is significantly higher compared with that for crack expansion. Hence, fractures of coal materials is mainly attributed to expansion and running through of the original microcracks under a low strain rate. With the increase of strain rate, the material absorbs a high level of energies before running through of microcracks, which are expandable, so that more microcracks can expand and thereby attend in the crushing process. Furthermore, more new cracks are generated, which requires higher-energy dissipation and decreases the particle diameter of crushed materials. Consequently, the critical stress for the material crushing is the higher. This interprets that the material strength increases with the increase of strain rate.

\subsection{Relations of Crushing Energy Density, Energy Dissipation} Rate, and Strain Rate. According to the stress-strain experimental results under varying dynamic loads and equations (1)-(7), the crushing energy density and energy dissipation rate of coal samples could be calculated (Table 1).

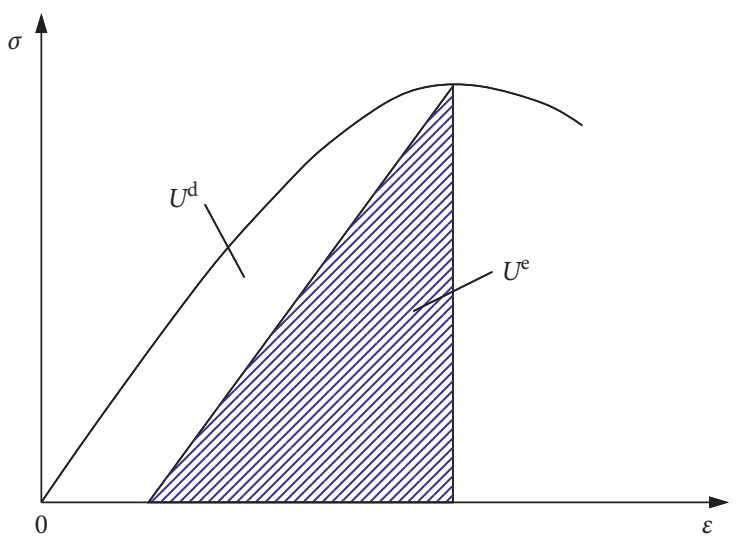

FIGURE 2: Relationship between dissipation energy and releasable elastic latent energy [36].

The relations of crushing energy density and strain rate are shown in Figure 4.

Seen from Figure 4, the crushing energy density of two types of coal specimens shows the relatively consistent variation laws (exponential growth) with strain rate. Crushing energy density of nonoutburst coal is the higher under the same strain rate. When the strain rate is low, the difference of crushing energy between outburst coal and nonoutburst coal is not very large, which is related with the preparation of nonoutburst coal specimens. The internal cracks of the drilled nonoutburst coal are kept well and can influence energy absorption to some extent. This is basically consistent with the energy dissipation laws of porous manmade rocks in the study of Xie [36]. When the strain rate is high, the difference of crushing energy between outburst and nonoutburst coal increases. This is because the nonoutburst coal has relatively high strength, and they have to consume more energy to generate the same crack. As seen from Table 1, the energy dissipation rate of both outburst coal and nonoutburst coal is basically consistent with the changes of strain rate. In other words, the energy dissipation rate is kept constant at about 10\% 20\%, and it is a variable unrelated with strain rate.

4.3. Relations of Total Absorption Energy Density, Elastic Latent Density, and Strain Rate. In order to compare and 


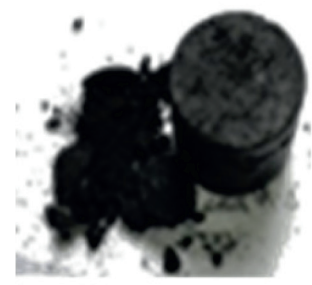

$81 \mathrm{~s}^{-1}$

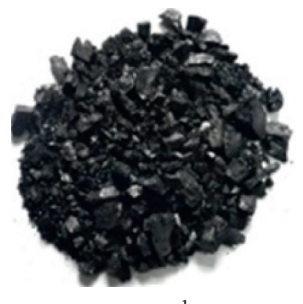

$81 \mathrm{~s}^{-1}$

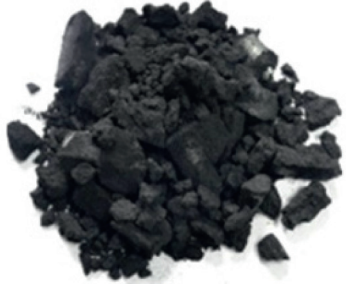

$129 \mathrm{~s}^{-1}$

(a)

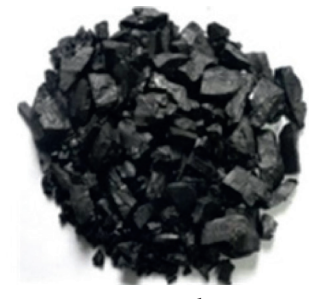

(b)

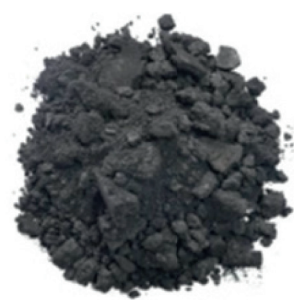

$193 \mathrm{~s}^{-1}$

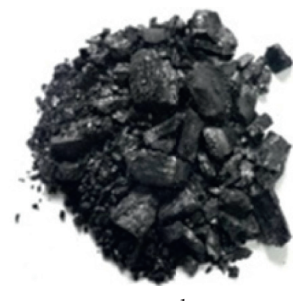

$193 \mathrm{~s}^{-1}$

FIgURE 3: Specimens after impacting. (a) Outburst coal. (b) Nonoutburst coal.

TABle 1: Energy of coal specimens under dynamic impact.

\begin{tabular}{|c|c|c|c|c|c|c|c|c|}
\hline Type & $\begin{array}{c}\text { Specimen } \\
\text { no. }\end{array}$ & $\begin{array}{c}\text { Strain } \\
\text { rate }\left(s^{-1}\right)\end{array}$ & $\begin{array}{l}\text { Incident } \\
\text { energy }(J)\end{array}$ & $\begin{array}{l}\text { Reflected } \\
\text { energy }(J)\end{array}$ & $\begin{array}{c}\text { Transmitted } \\
\text { energy }(\mathrm{J})\end{array}$ & $\begin{array}{l}\text { Crushing } \\
\text { energy }(J)\end{array}$ & $\begin{array}{l}\text { Crushing energy } \\
\text { density }\left(\mathrm{J} \cdot \mathrm{m}^{-3}\right)\end{array}$ & $\begin{array}{c}\text { Energy } \\
\text { dissipation rate }\end{array}$ \\
\hline \multirow{14}{*}{ Outburst coal } & D1 & 73 & 32.98 & 27.04 & 0.17 & 5.78 & 81563 & 0.175 \\
\hline & D2 & 78 & 57.21 & 48.58 & 0.12 & 8.51 & 128991 & 0.149 \\
\hline & D3 & 81 & 63.19 & 56.64 & 0.10 & 6.46 & 90996 & 0.102 \\
\hline & D4 & 101 & 166.70 & 130.64 & 0.15 & 35.91 & 156918 & 0.215 \\
\hline & D5 & 115 & 226.65 & 183.42 & 0.65 & 42.59 & 188245 & 0.188 \\
\hline & D6 & 129 & 268.20 & 218.20 & 0.52 & 49.48 & 219607 & 0.184 \\
\hline & D7 & 160 & 424.55 & 344.91 & 0.50 & 79.14 & 345802 & 0.186 \\
\hline & D8 & 174 & 254.14 & 222.23 & 0.15 & 31.76 & 475742 & 0.206 \\
\hline & D9 & 193 & 609.29 & 494.99 & 0.79 & 113.51 & 499874 & 0.186 \\
\hline & D10 & 214 & 349.36 & 279.52 & 0.26 & 69.58 & 795067 & 0.149 \\
\hline & D11 & 219 & 391.21 & 328.17 & 0.29 & 62.75 & 951140 & 0.160 \\
\hline & D12 & 221 & 663.94 & 520.78 & 0.94 & 142.22 & 853109 & 0.173 \\
\hline & D13 & 268 & 497.17 & 400.90 & 0.67 & 95.61 & 1585950 & 0.192 \\
\hline & D14 & 279 & 518.02 & 430.40 & 0.55 & 87.07 & 1628234 & 0.187 \\
\hline \multirow{6}{*}{$\begin{array}{l}\text { Nonoutburst } \\
\text { coal }\end{array}$} & D15 & 96 & 85.70 & 75.15 & 0.82 & 9.72 & 159767 & 0.113 \\
\hline & D16 & 120 & 111.73 & 87.44 & 0.77 & 23.52 & 315228 & 0.211 \\
\hline & D17 & 125 & 117.27 & 90.56 & 0.80 & 25.91 & 435503 & 0.221 \\
\hline & D18 & 145 & 152.78 & 113.10 & 0.51 & 39.17 & 651923 & 0.256 \\
\hline & D19 & 177 & 242.73 & 184.94 & 0.70 & 57.09 & 944028 & 0.235 \\
\hline & D20 & 186 & 304.03 & 232.57 & 1.23 & 70.23 & 1391585 & 0.231 \\
\hline
\end{tabular}

analyze the energy absorption law of coal specimen under impact loading and quasi-static loading, the elastic latent energy density and total absorption energy density of two types of coal specimen are calculated according to the stressstrain curves under quasi-static loading, as shown in Table 2. According to stress-strain experimental results under varying dynamic loads and equations (8)-(10), the total absorption energy density and elastic latent density are calculated, as shown in Table 3. The ratio of absorption energy (Table 3 ) is defined as the ratio of absorption energy of specimens under varying strain rates and absorption energy under static failure. The ratio of elastic latent energy (Table 3) is defined as elastic latent energy of specimens under varying strain rates and elastic latent energy under static failure.

The relations of total absorption energy density and ratio of absorption energy of two types of coal specimens with strain rate under different impact loads are shown in Figure 5. The total absorption energy density of nonburst coal is higher compared with that of outburst coal, indicating that the total absorption energy density of nonburst coal is more sensitive to strain rate. Because outburst coal is relatively 


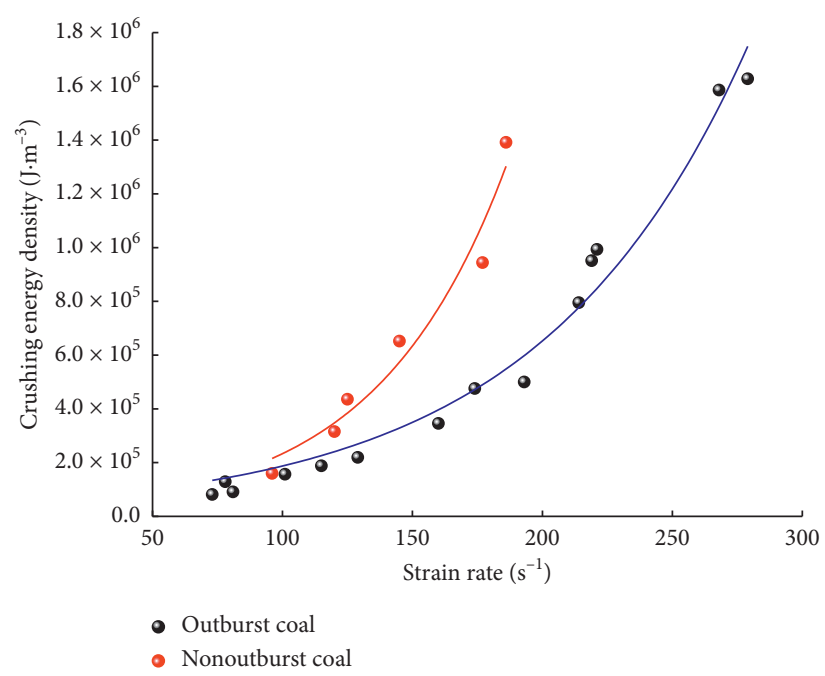

FIGURE 4: Relations of crushing energy density and strain rate.

TABLe 2: Elastic latent energy density and total absorption energy density of static test.

\begin{tabular}{lcccc}
\hline Type & Specimen no. & Peak strain $\left(10^{-4}\right)$ & Elastic latent energy density $\left(\mathrm{J} \cdot \mathrm{m}^{-3}\right)$ & ${\text { Total absorption energy density }\left(\mathrm{J} \cdot \mathrm{m}^{-3}\right)}^{*}$ Nonoutburst coal \\
& S1 & 66.63 & 53736.92 & 58314.13 \\
& S2 & 72.88 & 47401.89 & 56662.66 \\
& S3 & 65.23 & 53058.81 & 61283.68 \\
& Average & 63.94 & 51399.21 & 58753.49 \\
\multirow{3}{*}{ Outburst coal } & S4 & 193.2 & 14383.48 & 22659.44 \\
& S5 & 214.4 & 14104.76 & 23644.62 \\
& Average & 203.80 & 14244.12 & 23152.03 \\
\hline
\end{tabular}

TABLe 3: Absorption energy density and elastic latent energy density of coal specimens under impact loads.

\begin{tabular}{|c|c|c|c|c|c|c|}
\hline Type & $\begin{array}{c}\text { Specimen } \\
\text { no. }\end{array}$ & $\begin{array}{c}\text { Strain rate } \\
\left(\mathrm{s}^{-1}\right)\end{array}$ & $\begin{array}{c}\text { Elastic latent } \\
\text { density }\left(\mathrm{J} \cdot \mathrm{m}^{-3}\right) \\
\end{array}$ & $\begin{array}{c}\text { Total absorption energy } \\
\text { density }\left(\mathrm{J} \cdot \mathrm{m}^{-3}\right)\end{array}$ & $\begin{array}{c}\text { Ratio of elastic } \\
\text { latent energy }\end{array}$ & $\begin{array}{c}\text { Ratio of total } \\
\text { absorption energy }\end{array}$ \\
\hline \multirow{14}{*}{ Outburst coal } & D1 & 73 & 7514.4 & 15164.3 & 0.53 & 0.65 \\
\hline & D2 & 78 & 10462.4 & 20737.6 & 0.73 & 0.90 \\
\hline & D3 & 81 & 10924.5 & 18650.5 & 0.77 & 0.81 \\
\hline & D4 & 101 & 5820.8 & 15484.3 & 0.35 & 0.67 \\
\hline & D5 & 115 & 28707.9 & 53413.8 & 2.02 & 2.31 \\
\hline & D6 & 129 & 21715.6 & 43215.1 & 1.52 & 1.87 \\
\hline & D7 & 160 & 24476.2 & 45100.0 & 1.72 & 1.95 \\
\hline & D8 & 174 & 36180.2 & 74123.9 & 2.54 & 3.20 \\
\hline & D9 & 193 & 43826.1 & 80153.5 & 3.08 & 3.46 \\
\hline & D10 & 214 & 40665.1 & 76023.1 & 2.85 & 3.28 \\
\hline & D11 & 219 & 51529.5 & 94275.0 & 3.62 & 4.07 \\
\hline & D12 & 221 & 47259.1 & 84470.3 & 3.32 & 3.65 \\
\hline & D13 & 268 & 96275.4 & 175133.1 & 6.76 & 7.56 \\
\hline & D14 & 279 & 107619.6 & 207698.7 & 7.56 & 8.97 \\
\hline \multirow{6}{*}{$\begin{array}{l}\text { Nonoutburst } \\
\text { coal }\end{array}$} & D15 & 96 & 12354.2 & 30345.0 & 0.24 & 0.52 \\
\hline & D16 & 120 & 22291.0 & 45932.7 & 0.43 & 0.78 \\
\hline & D17 & 125 & 21409.3 & 46927.4 & 0.42 & 0.66 \\
\hline & D18 & 145 & 33695.8 & 59910.0 & 0.66 & 1.02 \\
\hline & D19 & 177 & 47037.3 & 90295.5 & 0.92 & 1.54 \\
\hline & D20 & 186 & 66647.1 & 123949.5 & 1.30 & 2.11 \\
\hline
\end{tabular}


soft, they can absorb less energy and experience the hardening effect with the increase of strain rate under static failure mode. The outburst coal shows the higher ratio of absorption energy under impact load-induced failures than nonburst coal, which explains why soft coals are easier to be damaged upon energy accumulation under disturbance loads like rock burst.

As seen from Figure 5(a), the absorption energy density with crushing of two types of coal specimens achieves an exponential growth with the increase of strain rate $(\dot{\varepsilon})$ in the experiment. The fitting relations can be expressed as

$$
\begin{aligned}
& \text { nonoutburst coal : } u=7076 e^{0.015 \dot{\varepsilon}}, \\
& \text { nonoutburst coal }: u=3304 e^{0.015 \dot{\varepsilon}} \text {. }
\end{aligned}
$$

According to the fitting expressions, two types of coal specimens show the same growth trend of total absorption energy density, indicating that the outburst coal and nonoutburst coal show consistent responses to the impact loading.

Relations of releasable elastic latent energy density and ratio of elastic latent energy of two types of coal specimens with strain rate under the impact loads are shown in Figure 6. Obviously, releasable elastic latent energy density of two types of coal specimens grows quickly with the increase of strain rate. They both show significant correlations with strain rate. The relevant relations can be expressed in the (13) and (14). The elastic latent density of nonoutburst coal is higher compared with that of outburst coal under different strain rates. In other words, nonoutburst coal can release more energy for damages. Seen from Figure 6(b), the ratio of elastic latent energy of outburst coal is higher under the same strain rate, and the outburst coal can release more times of energy compared with that under static failure. Moreover, outburst coal requires less energy to be fractured. As a result, energy released by the outburst coal is easier to cause failure damages of coals. This also explains the easier occurrence of dynamic phenomenon in the soft seams (there is a layer of soft seam in hard coals) of coals.

$$
\begin{aligned}
\text { Nonoutburst coal : } U^{e} & =2644 e^{0.017 \dot{\varepsilon}}, \\
\text { outburst coal }: U^{e} & =3827 e^{0.012 \dot{\varepsilon}} .
\end{aligned}
$$

Based on fitting results, the nonoutburst coal can absorb more energy and contain more releasable elastic latent energy than outburst coal before failure under the same intensity of impact loads.

\subsection{Relations of Total Absorption Energy Density and Elastic} Latent Density with Dynamic Strength. Relations total absorption energy density and elastic latent energy density with dynamic strength of coal is shown in Figures 7 and 8, respectively. It can be seen from Figures 7(a) and 8(a) that dynamic strength of coal is the major influencing factor of absorption energy of different coals. The energy absorption of both outburst coal and nonoutburst coal under the same peak strength is almost the same. However, the nonoutburst coal has the higher peak strength under the same strain rate due to the relatively higher hardness, thus showing the higher energy absorption and storage. Because ductile materials have a process of transforming from ductility to brittleness under the high strain rate (which is known as the strain rate-induced hardening effect) and the static crushing energy of outburst coal is relatively low, the outburst coal can absorb and store more times of energy for crushing than the nonoutburst coal under statistic test (Figures 7(b) and 8(b)).

4.5. Relations of Energy Density and Fractal Dimension with Mean Particle Diameter. Generally, the mass-frequency distribution of fragments observes the following laws $[11,37]$ :

$$
\frac{M(R)}{M}=1-\exp \left[-\left(\frac{R}{R_{0}}\right)^{b}\right],
$$

where $M(R)$ is the cumulative mass of fragments with diameter smaller than $R(\mathrm{~kg}), M$ is the total mass of fragments $(\mathrm{kg})$, and $R_{0}$ is scale parameter of the fragment distribution and related to the mean size. According to relevant studies $[37,38], D=3-b$, where $D$ is the fractal dimension of fragments. The screening statistics and fractal computing results of fragments of outburst and non-outburst coal are listed in Table 4.

As seen from Table 4, with the increase of strain rate (impact loading energy) in the experiment, the proportions of small fragments of outburst and nonoutburst coal show an increasing trend after the failure, and the degree of impact crushing of coal specimen increases, the fractal dimension of fragments increases. As coal is geologic material, part of the experimental data in Table 4 is discrete, but the overall trend is consistent with the above conclusion. The relations of crushing energy density, absorption energy density, and fractal dimension are shown in Figure 9. The fractal dimension $(D)$ of outburst and nonoutburst coal presents an evident logarithmic growth with the increase of crushing energy density and absorption energy density, indicating that the higher degree of crushing requires a larger impact energy to the specimens. This is basically consistent with other studies on fractal behaviors of rock [39], anthracite [40], and other materials under in impact experiments. Moreover, the proportion of small fragment of outburst coal is the higher when the energy absorption and storage are the same. This conforms to the previous analyses that the proportion of energy to damage the outburst coal is the higher given the same energy condition.

For quantitative description of degree of crushing after the impact test, the mean particle diameter of the certain coal specimen all fragments was defined as

$$
\bar{d}=\frac{\sum \bar{d}_{i} \eta_{i}}{\sum \eta_{i}}
$$

where $\bar{d}$ is the mean particle diameter of the certain coal specimen all fragments $(\mathrm{mm}), \bar{d}_{i}$ is the mean particle diameter of fragments retained in sieves with certain pore 


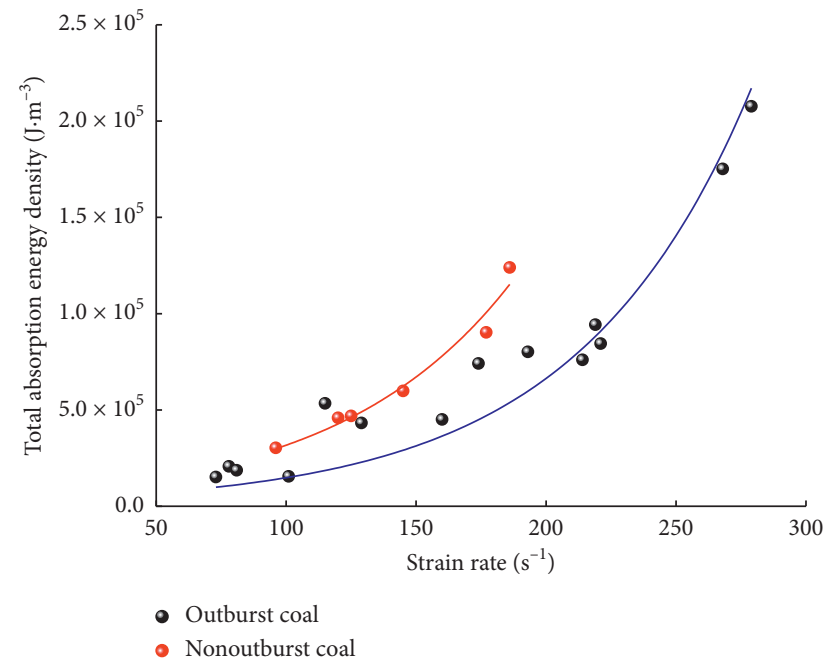

(a)

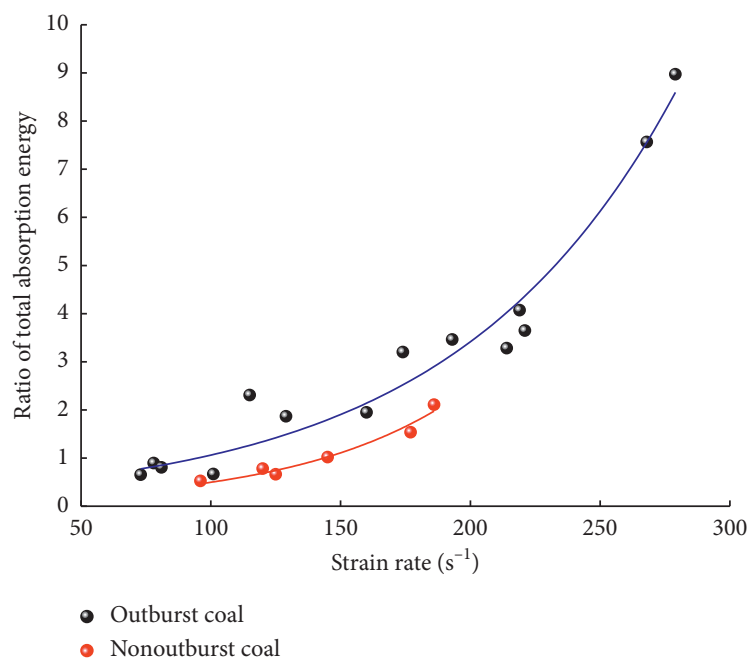

(b)

Figure 5: Relations of total absorption energy density, ratio of absorption energy, and strain rate. (a) Total absorption energy density; (b) ratio of absorption energy.

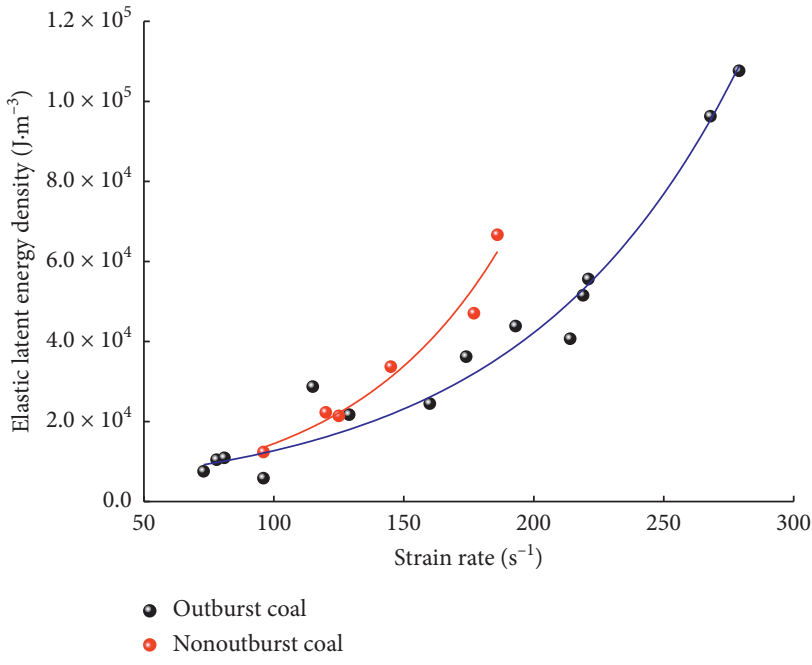

(a)

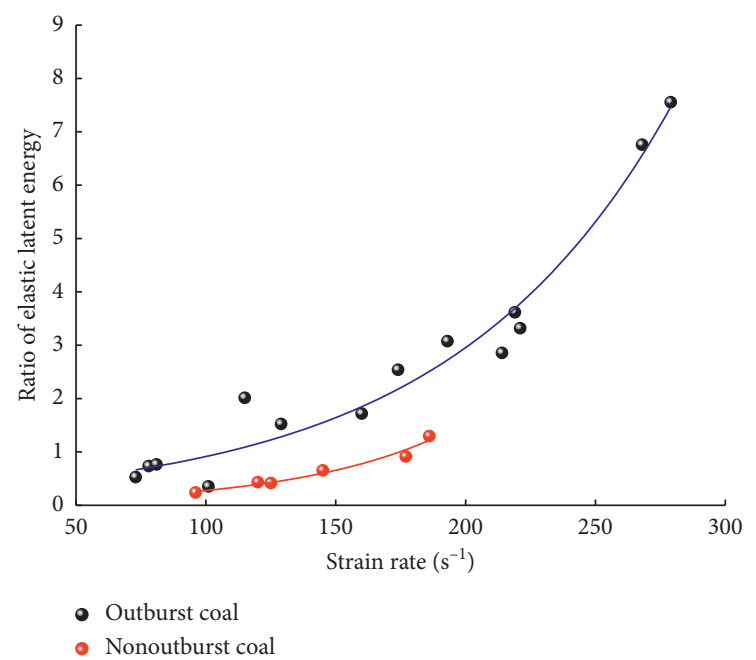

(b)

Figure 6: Relations of elastic latent energy density, ratio of elastic latent energy, and strain rate. (a) Elastic latent energy density; (b) ratio of elastic latent energy.

diameter during the screening process $(\mathrm{mm})$, and $\eta_{i}$ is the mass percentage of fragments intercepted by a certain diameter of pores (\%).

The relationship between mean particle diameter of fragments and energy is shown in Figure 10. With the increase of energy absorption and storage, the mean particle diameter of fragments decreases exponentially, and such reduction is quicker in outburst coal. Due to various natural fractures and defects, the mean particle diameter of fragments of nonoutburst coal is smaller than that of outburst coal (compacted into internally uniform) when there is less impact energy under the low strain rate. A lot of new cracks will be formed before running through of original cracks and defects. Because nonoutburst coal consume plenty of energy for form new cracks because of the high strength, the mean particle diameter of fragments of outburst coal begins to be smaller than that of nonoutburst coal under the relatively high impact energy. 


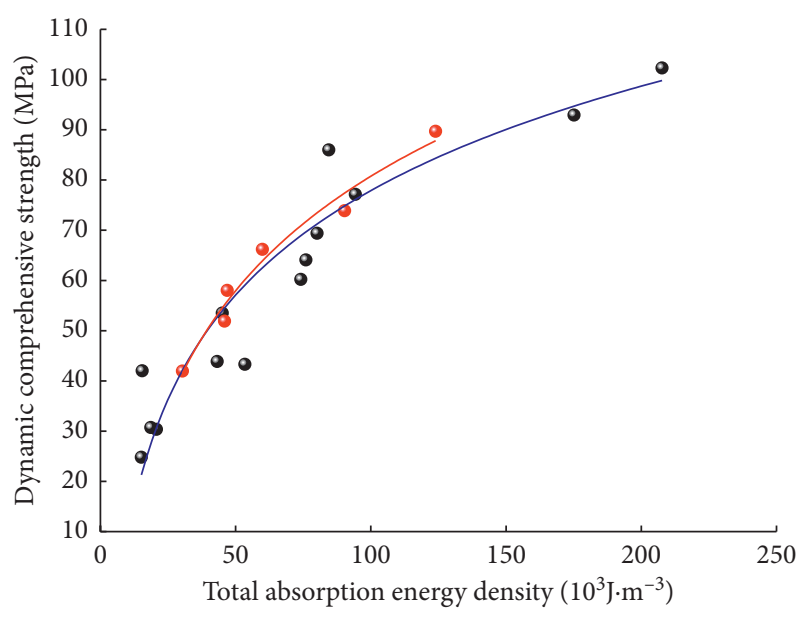

- Outburst coal

- Nonoutburst coal

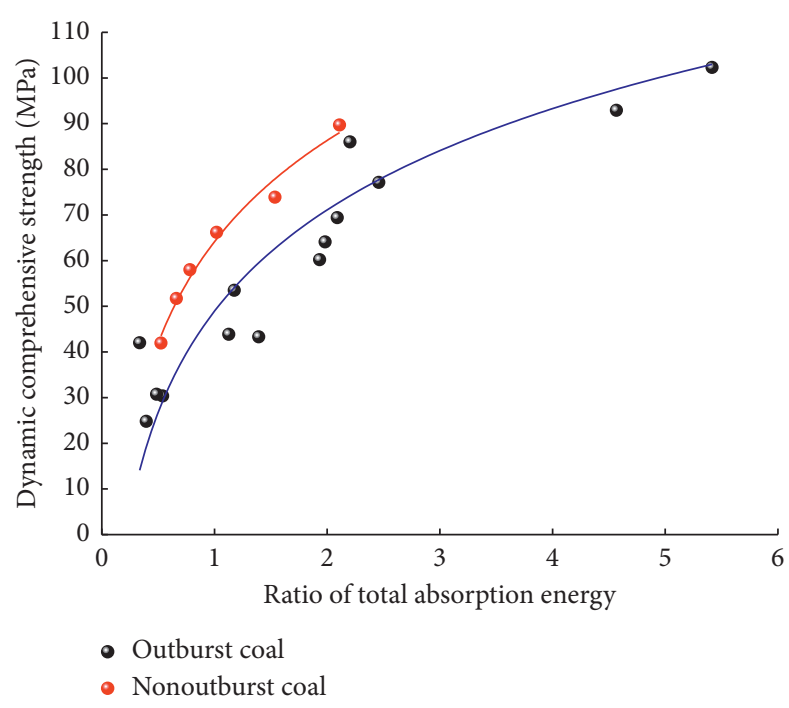

(b)

Figure 7: Relations of total absorption energy density, ratio of absorption energy, and dynamic strength. (a) Total absorption energy density; (b) ratio of total absorption energy.

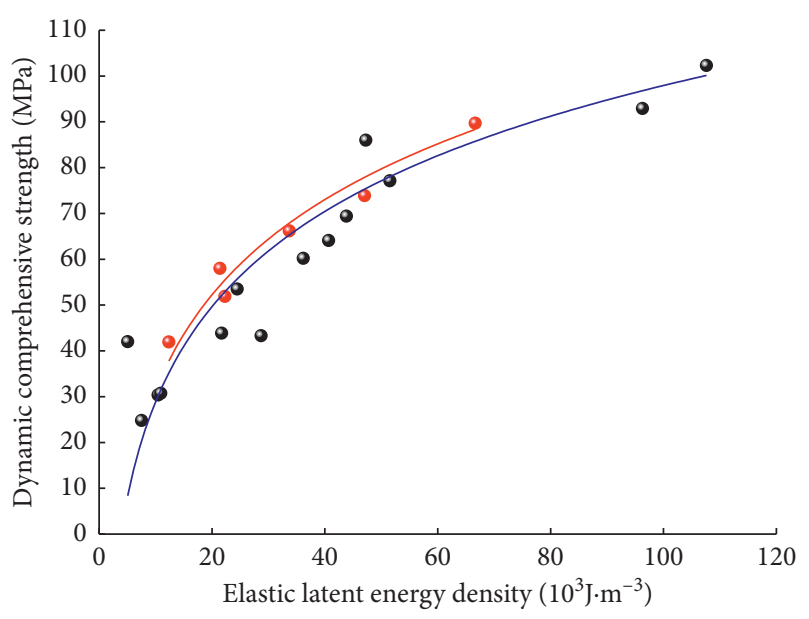

- Outburst coal

- Nonoutburst coal

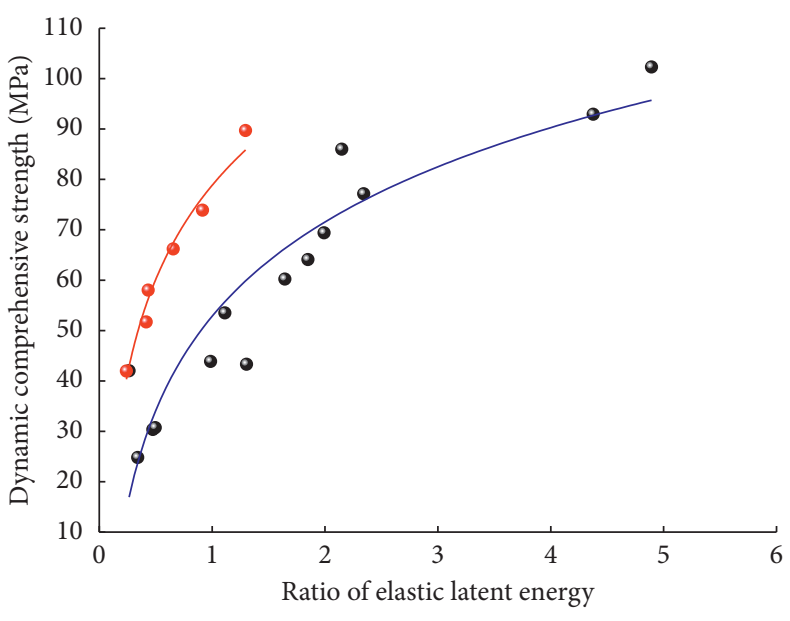

- Outburst coal

- Nonoutburst coal

(a)

(b)

FIGURE 8: Relations of elastic latent energy density, ratio of elastic latent, and dynamic strength. (a) Elastic latent energy density; (b) ratio of elastic latent energy. 
TABLE 4: The screening statistics and fractal computing results of fragments of outburst and nonoutburst coal.

\begin{tabular}{|c|c|c|c|c|c|c|c|c|c|c|c|}
\hline Type & $\begin{array}{l}\text { Specimen } \\
\text { no. }\end{array}$ & $\begin{array}{c}\text { Strain } \\
\text { rate } \\
\left(\mathrm{s}^{-1}\right)\end{array}$ & $\begin{array}{r}\text { The } c \\
<0.5 \mathrm{~mm}\end{array}$ & $\begin{array}{l}\text { umulativ } \\
<1 \mathrm{~mm}\end{array}$ & $\begin{array}{l}<10 \mathrm{~mm} \\
\text { re mass ur }\end{array}$ & $\begin{array}{l}\text { ader the si } \\
<20 \mathrm{~mm}\end{array}$ & $\begin{array}{l}\text { ieve/g } \\
<30 \mathrm{~mm}\end{array}$ & $\begin{array}{l}\text { Total mass of } \\
\text { fragments }(\mathrm{g})\end{array}$ & $\begin{array}{l}\text { Specimen } \\
\text { mass (g) }\end{array}$ & $b$ & $\begin{array}{c}\text { Fractal } \\
\text { dimension } D\end{array}$ \\
\hline \multirow{14}{*}{ Outburst coal } & D1 & 73 & 0.2 & 0.5 & 2.2 & 3.5 & 3.5 & 77.8 & 78.6 & 0.63 & 2.37 \\
\hline & D2 & 78 & 0.8 & 0.9 & 5.3 & 6.7 & 6.7 & 79.0 & 79.2 & 0.59 & 2.41 \\
\hline & D3 & 81 & 0.8 & 1.1 & 3.8 & 6.9 & 8.5 & 85.3 & 85.5 & 0.58 & 2.42 \\
\hline & D4 & 102 & 11 & 14.7 & 47.5 & 67.5 & 78.3 & 78.3 & 79.9 & 0.49 & 2.51 \\
\hline & D5 & 115 & 12.2 & 16.6 & 49.6 & 66.8 & 76.4 & 76.4 & 78.8 & 0.42 & 2.58 \\
\hline & D6 & 129 & 13.2 & 18.2 & 52.6 & 68.5 & 77.2 & 77.2 & 79.7 & 0.70 & 2.30 \\
\hline & D7 & 160 & 14.5 & 19.3 & 57.4 & 69.3 & 75.9 & 75.9 & 78.2 & 0.44 & 2.56 \\
\hline & D8 & 174 & 15.6 & 20.6 & 59.7 & 72.2 & 75.3 & 75.3 & 79.8 & 0.40 & 2.60 \\
\hline & D9 & 193 & 17.1 & 22.1 & 60.3 & 70.5 & 74.8 & 74.8 & 76.9 & 0.46 & 2.54 \\
\hline & D10 & 214 & 19.4 & 25.1 & 65.5 & 69.9 & 69.9 & 69.9 & 77.5 & 0.34 & 2.66 \\
\hline & D11 & 219 & 17.4 & 22.6 & 58.9 & 71.6 & 71.6 & 71.6 & 79.3 & 0.37 & 2.63 \\
\hline & D12 & 221 & 17.5 & 23.4 & 63.5 & 68.3 & 68.3 & 68.3 & 73.6 & 0.52 & 2.48 \\
\hline & D13 & 268 & 17.3 & 22.3 & 62.9 & 66.5 & 66.5 & 66.5 & 74.6 & 0.36 & 2.64 \\
\hline & D14 & 279 & 16.6 & 21.3 & 58.3 & 64.2 & 64.2 & 64.2 & 72.7 & 0.36 & 2.64 \\
\hline \multirow{6}{*}{$\begin{array}{l}\text { Nonoutburst } \\
\text { coal }\end{array}$} & D15 & 96 & 0.1 & 1.3 & 38.5 & 87.1 & 87.1 & 87.1 & 89.2 & 1.61 & 1.39 \\
\hline & D16 & 120 & 0.3 & 2.0 & 39.2 & 75.4 & 76.8 & 76.8 & 79.4 & 1.46 & 1.54 \\
\hline & D17 & 125 & 0.4 & 2.5 & 50.5 & 71.5 & 75.6 & 75.6 & 83.0 & 1.27 & 1.73 \\
\hline & D18 & 145 & 2.5 & 5.7 & 48 & 80 & 90.1 & 90.1 & 86.9 & 0.89 & 2.11 \\
\hline & D19 & 177 & 2.2 & 6.3 & 54.6 & 75 & 77 & 77 & 82.5 & 0.80 & 2.20 \\
\hline & D20 & 186 & 1.4 & 5 & 59.4 & 76 & 76 & 76 & 83.7 & 0.69 & 2.31 \\
\hline
\end{tabular}

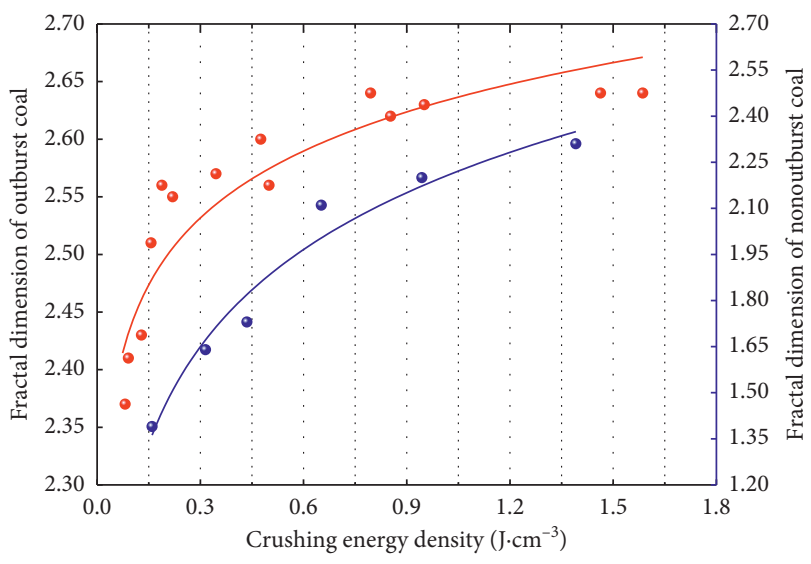

- Outburst coal

- Nonoutburst coal

(a)

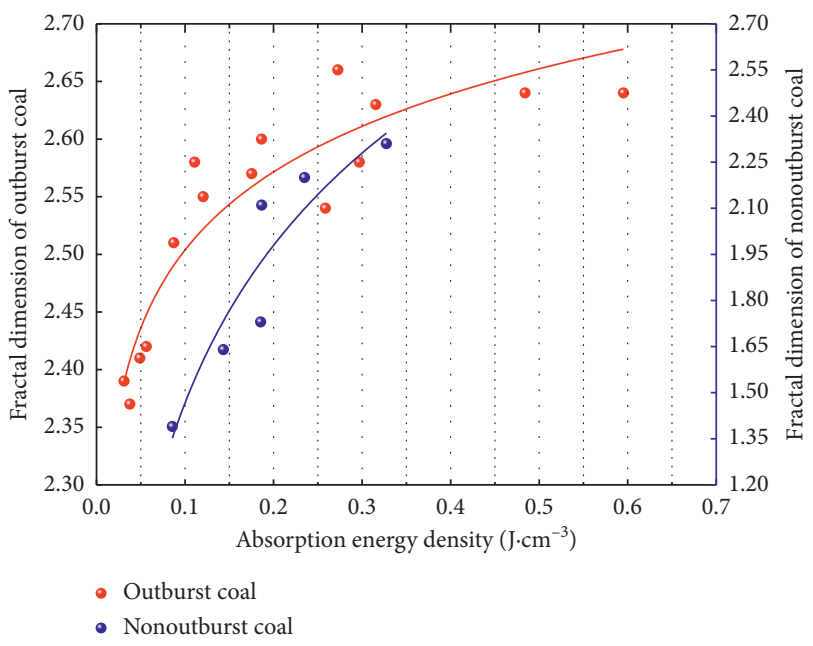

(b)

FiguRE 9: Relations of crushing energy density, absorption energy density and dynamic strength. (a) Crushing energy density; (b) absorption energy density. 


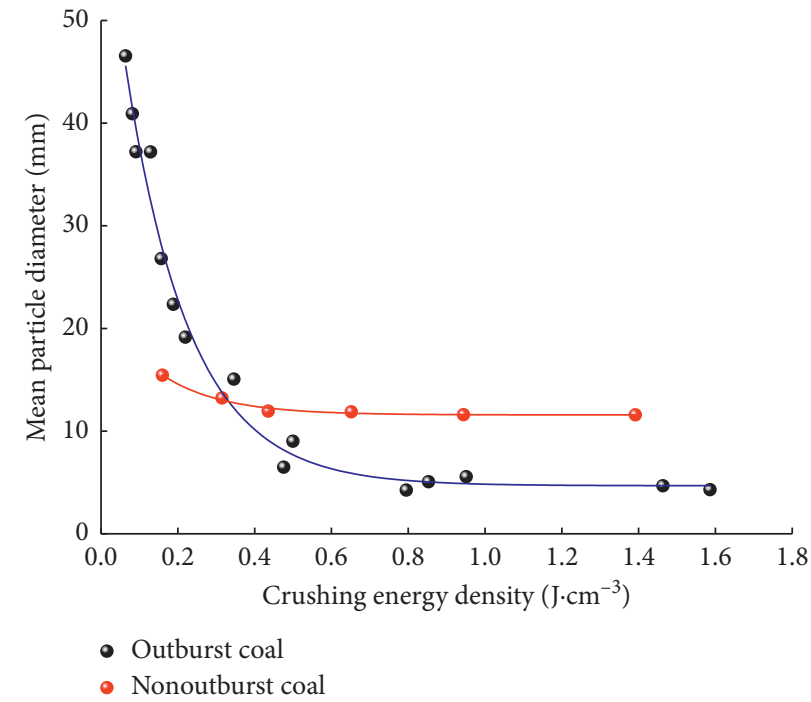

(a)

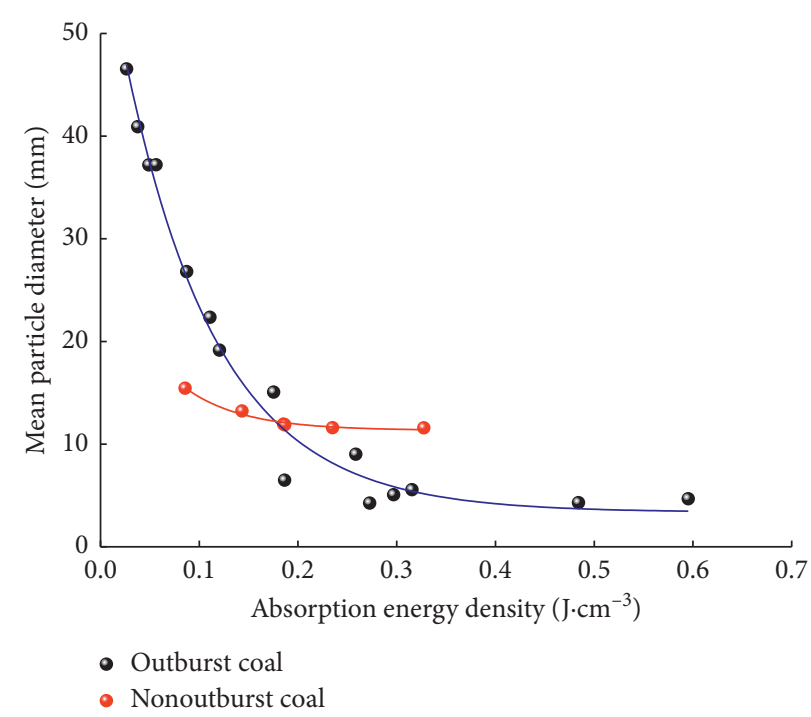

(b)

FIGURE 10: Relations of crushing energy density, absorption energy density, and mean particle diameter. (a) Crushing energy density; (b) absorption energy density.

\section{Conclusions}

(1) Given the impact loads, crushing energy of coal is closely related with strain rate. Crushing energy shows an exponential growth with the increase of strain rate, indicating that more energy is used to damage the specimens. However, the energy dissipation rate of both outburst coal and nonoutburst coal is basically constant. In other words, energy dissipation rate is kept constant at about $10 \% \sim 20 \%$, and it is a variable unrelated with strain rate.

(2) With the increase of experimental strain rate, the absorption energy for the damage of coal and rock achieves an exponential growth, indicating that more energy is used to promote crack expansion and damage of specimens with the increase of loading strength. Moreover, outburst coal and nonoutburst coal show consistent responses to loads.

(3) There is a good logarithmic relation between the dynamic compressive strength of coal and absorption energy density and elastic latent energy density. Bot nonoutburst coal and outburst coal show almost the same energy adsorption under the same peak strength. Due to the higher hardness, the nonoutburst coal has the higher peak strength given the same strain rate, so they have to absorb and store more energy. However, the outburst coal can absorb and store more times of energy for breakage than nonoutburst coals under the static test.

(4) Fractal features of coal fragments under dynamic impacts are significantly. Moreover, fractal dimension and degree of fracture of specimens are positively related with strain rate, whereas mean particle diameter of fragment is negatively related. There is a logarithmic growth relationship between the fractal dimension and strain rate. Moreover, the mean particle diameter of experimental fragment basically meets the negative exponential relationship with strain rate, indicating that coals need more energy to be broken into smaller pieces.

\section{Data Availability}

All data included in this study are available upon request by contacting the corresponding author.

\section{Conflicts of Interest}

The authors declare that there are no conflicts of interest regarding the publication of this article.

\section{Acknowledgments}

This work was supported by the University Natural Science Foundation of Anhui Province (KJ2019A0098, KJ2017A091, and 1808085ME160).

\section{References}

[1] H. Lawson, A. Weakley, and A. Miller, "Dynamic failure in coal seams: implications of coal composition for bump susceptibility," International Journal of Mining Science and Technology, vol. 26, no. 1, pp. 3-8, 2016.

[2] B. B. Beamish and P. J. Crosdale, "Instantaneous outbursts in underground coal mines: an overview and association with coal type," International Journal of Coal Geology, vol. 35, no. 1-4, pp. 27-55, 1998.

[3] C. Mark and M. Gauna, "Evaluating the risk of coal bursts in underground coal mines," International Journal of Mining Science and Technology, vol. 26, no. 1, pp. 47-52, 2016. 
[4] H. Q. Zhu, S. H. Fang, Y. L. Zhang et al., "Study on the dynamic response characteristics of cylindrical coal-rock samples under dynamic loads," Shock and Vibration, vol. 2020, Article ID 8820316, 12 pages, 2020.

[5] Z. T. Bieniawski and M. J. Bernede, "Suggested methods for determining the uniaxial compressive strength and deformability of rock materials," International Journal of Rock Mechanics and Mining Science \& Geomechanics Abstracts, vol. 16, no. 2, pp. 137-140, 1979.

[6] H. Zhang, Z. Wan, D. Ma, Y. Zhang, J. Cheng, and Q. Zhang, "Experimental investigation on the strength and failure behavior of coal and synthetic materials under plane-strain biaxial compression," Energies, vol. 10, no. 4, pp. 500-514, 2017.

[7] F. Gao and H. Kang, "Experimental study on the residual strength of coal under low confinement," Rock Mechanics and Rock Engineering, vol. 50, no. 2, pp. 285-296, 2017.

[8] B. B. Wu, R. Chen, and K. Xia, "Dynamic tensile failure of rocks under static pre-tension," International Journal of Rock Mechanics and Mining Sciences, vol. 80, pp. 12-18, 2015.

[9] S. Gong, Z. Wang, L. Zhou et al., "Influence of cyclic impact loading and axial stress on dynamic mechanical properties of burst-prone coal," Shock and Vibration, vol. 2021, Article ID 6649308, 10 pages, 2021.

[10] M. H. Ju, X. F. Li, and J. C. Li, "Large-scale asymmetric pulverization of fault zone: insights from rock axial strain in static and dynamic loading conditions," International Journal of Rock Mechanics and Mining Sciences, vol. 137, 2020.

[11] X. F. Li, H. B. Li, Q. B. Zhang, J. L. Jiang, and J. Zhao, "Dynamic fragmentation of rock material: characteristic size, fragment distribution and pulverization law," Engineering Fracture Mechanics, vol. 199, pp. 739-759, 2018.

[12] F. G. Zeng, "Grinding kinetic equation of coal characterized by particle size," Journal of China Coal Society, vol. 25, pp. 303-306, 2000.

[13] H. X. Jiang, C. L. Du, and S. Y. Liu, "The effects of impact velocity on energy and size distribution of rock crushing," Journal of China Coal Society, vol. 38, pp. 604-610, 2013.

[14] J. Luo, G. Huang, L. Zhang, F. Huang, and J. Zheng, "Micro shape of coal particle and crushing energy," International Journal of Mining Science and Technology, vol. 28, no. 6, pp. 1009-1014, 2018.

[15] D. N. Whittles, S. Kingman, I. Lowndes, and K. Jackson, "Laboratory and numerical investigation into the characteristics of rock fragmentation," Minerals Engineering, vol. 19, no. 14, pp. 1418-1429, 2006.

[16] D. J. Reddish, L. R. Stace, P. Vanichkobchinda, and D. N. Whittles, "Numerical simulation of the dynamic impact breakage testing of rock," International Journal of Rock Mechanics and Mining Sciences, vol. 42, no. 2, pp. 167-176, 2005.

[17] L. M. Tavares, "Energy absorbed in breakage of single particles in drop weight testing," Minerals Engineering, vol. 12, no. 1, pp. 43-50, 1999.

[18] B. Magnus and E. C. Magnus, "Measuring characteristics of aggregate material from vertical shaft impact crushers," Minerals Engineering, vol. 19, pp. 1479-1486, 2006.

[19] T. Yan, W. Li, X. L. Bi et al., "A new evaluation method for rock-crushing efficiency based on crushing work ratio," Acta Petrologica Sinica, vol. 30, pp. 291-294, 2009.

[20] A. Carpinteri and N. Pugno, "One, two, and three-dimensional universal laws for fragmentation due to impact and explosion," Journal of Applied Mechanics, vol. 69, no. 6, pp. 854-856, 2002.
[21] C. Wang, Y. Cheng, M. Yi, B. Hu, and Z. Jiang, "Surface energy of coal particles under quasi-static compression and dynamic impact based on fractal theory," Fuel, vol. 264, Article ID 116835, 2020.

[22] D. Maugis, "Subcritical crack growth, surface energy, fracture toughness, stick-slip and embrittlement," Journal of Materials Science, vol. 20, no. 9, pp. 3041-3073, 1985.

[23] S. Takaomi and O. Masayuki, "Specific surface free energy and the morphology of synthesized ruby single crystals," Journal of Crystal Growth, vol. 318, pp. 76-78, 2011.

[24] E. T. Stamboliadis, "The energy distribution theory of comminution specific surface energy, mill efficiency and distribution mode," Minerals Engineering, vol. 20, no. 2, pp. 140-145, 2007.

[25] E. Gaziev, "Rupture energy evaluation for brittle materials," International Journal of Solids and Structures, vol. 38, no. 4243, pp. 7681-7690, 2001.

[26] E. G. Gaziev, "Strength and deformability of brittle polycrystalline materials in multiaxial stress-strain state: rupture energy evaluation for brittle materials," Geomechanics and Geodynamics of Rock Masses, vol. 1, pp. 31-40, 2018.

[27] A. Sainoki, H. S. Mitri, D. Chinnasane, and A. K. Schwartzkopff, Quantitative energy-based evaluation of the intensity of mining-induced seismic activity in a fractured rock mass," Rock Mechanics and Rock Engineering, vol. 52, no. 11, pp. 4651-4667, 2019.

[28] H. L. Gu, M. Tao, X. B. Li et al., "The effects of water content and external incident energy on coal dynamic behaviour," International Journal of Rock Mechanics and Mining Sciences, vol. 123, Article ID 104088, 2019.

[29] J. Feng, E. Wang, X. Chen, and H. Ding, "Energy dissipation rate: an indicator of coal deformation and failure under static and dynamic compressive loads," International Journal of Mining Science and Technology, vol. 28, no. 3, pp. 397-406, 2018.

[30] X. J. Hao, G. Y. Pan, C. X. Ma et al., "Failure behavior and energy storage and release of hard coal under different static and dynamic loading states," Advances in Civil Engineering, vol. 2020, Article ID 8837289, 14 pages, 2020.

[31] O. Vardar, C. Zhang, I. Canbulat, and B. Hebblewhite, "Numerical modelling of strength and energy release characteristics of pillar-scale coal mass," Journal of Rock Mechanics and Geotechnical Engineering, vol. 11, no. 5, pp. 935-943, 2019.

[32] Z. Lu, W. Ju, F. Gao et al., "A new bursting liability evaluation index for coal -the effective elastic strain energy release rate," Energies, vol. 12, no. 19, p. 3734, 2019.

[33] C. G. Zhang, F. Tahmasebinia, I. Canbulat et al., "Analytical determination of energy release in a coal mass," Energies, vol. 11, no. 2, p. 285, 2018.

[34] R. Peng, Y. Ju, J. G. Wang, H. Xie, F. Gao, and L. Mao, “Energy dissipation and release during coal failure under conventional triaxial compression," Rock Mechanics and Rock Engineering, vol. 48, no. 2, pp. 509-526, 2015.

[35] B. Lundberg, "A split Hopkinson bar study of energy absorption in dynamic rock fragmentation," International Journal of Rock Mechanics and Mining Science \& Geomechanics Abstracts, vol. 13, no. 6, pp. 187-197, 1976.

[36] H. P. Xie, Y. Ju, L. Y. Li et al., "Energy mechanism of deformation and failure of rock masses," Chinese Journal of Rock Mechanics and Engineering, vol. 27, pp. 1729-1740, 2008.

[37] M. C. He, G. X. Yang, J. L. Miao et al., "Classification and research methods of rockburst experimental fragments," Chinese Journal of Rock Mechanics and Engineering, vol. 28, pp. 1521-1529, 2009. 
[38] Y. Liu, J. W. Zhou, and C. L. Du, "Fractal character of impact crushing granularity of coal lumps," Journal of Vibration and Shock, vol. 32, no. 3, pp. 18-21, 2013.

[39] W. X. Gao and Y. T. Liu, "Energy dissipation rock damage under impact loading," Chinese Journal of Rock Mechanics and Engineering, vol. 28, pp. 1777-1780, 2003.

[40] H. B. Zhao, Z. H. Li, S. H. Zhong et al., "Experimental study of mechanical properties of coal rock containing gas under uniaxial compression," Journal of Mining and Safety Engineering, vol. 27, pp. 131-134, 2010. 